\title{
Graft site and gonadotrophin stimulation influences the number and quality of oocytes from murine ovarian tissue grafts
}

\author{
Hsiao Yun Yang ${ }_{4}^{1}$ Shae-Lee Cox $^{1,2}$, Graham Jenkin ${ }^{1,2}$, Jock Findlay ${ }^{3}$, Alan Trounson ${ }^{2}$ \\ and Jillian Shaw \\ ${ }^{1}$ Department of Physiology, ${ }^{2}$ Monash Immunology and Stem Cell Laboratories, ${ }^{3}$ Prince Henry's Institute of \\ Medical research, Monash Medical Centre, Clayton, Australia 3168 and ${ }^{4}$ Department of Anatomy and Cell \\ Biology, Monash University, Clayton, Australia 3800
}

Correspondence should be addressed to HY Yang; Email: Hsiao.yang@med.monash.edu.au

\begin{abstract}
Ovarian tissue cryopreservation and subsequent transplantation can restore fertility in cancer patients. This study used a mouse ovarian grafting model to investigate whether the graft site (bursal cavity, the kidney capsule or subcutaneous) influences the number, fertilization rate and developmental potential of oocytes recovered from grafts and whether using a standard gonadotrophin stimulation protocol would increase oocyte yield from the grafts. Mouse ovarian tissue was grafted into four week old mice and collected three weeks later. Graft recipients were treated either with or without exogenous gonadotrophin stimulation prior to graft collection. Grafted ovaries yielded oocytes that were either at the germinal vesicle (GV) stage or mature metaphase II (MII) stage at collection. These GV oocytes were matured before in vitro fertilization (IVF), while the MII oocytes underwent IVF immediately. Oocytes collected from the oviducts of non-grafted superovulated mice of the same age served as controls. Two-cell embryos were transferred to pseudopregnant recipients and recovered at day 15 of gestation or left to go to term. Graft retrieval and the number of oocytes from each graft were lowest from the subcutaneous graft site. The number of two-cell embryos produced was significantly higher for oocytes from the grafts to the bursa as compared with the other sites. All graft sites gave rise to embryos with comparable implantation rates and developmental potential to fetuses and offspring following transfer. However, the oocytes from grafted ovaries had a significantly lower developmental potential when compared with the control group. Stimulation with exogenous gonadotrophins did not significantly increase oocyte yield from grafted ovaries but did enhance oocyte maturation and development. In conclusion, graft site affects the number and quality of oocytes produced from ovarian grafts.

Reproduction (2006) $131851-859$
\end{abstract}

\section{Introduction}

Patients who require treatments that can compromise oocyte survival, e.g. chemo- and radiotherapy, can chose to have pieces of their ovarian tissue collected and cryopreserved in the anticipation of preserving their fertility. The birth of a naturally conceived baby from a cryopreserved ovarian graft suggests that autotransplantation of ovarian tissue can restore fertility to patients recovering from cancer (Donnez et al. 2004, Meirow et al. 2005, Siegel-Itzkovich 2005). The births confirm animal studies in which fresh and frozen ovarian tissue grafts restore cyclic hormonal function and give rise to live young (Gosden et al. 1994, Cox et al. 1996, Candy et al. 2000, Petroianu et al. 2002, Salle et al. 2002, Wang et al. 2002b, Oktay et al. 2003, Almodin et al. 2004b, Snow et al.
2004). The question that now emerges is whether the choice of graft site affects oocyte survival and viability which may in turn influence a patient's capacity to conceive following ovarian grafting.

Research on animals has shown that live young can be obtained from oocytes of ovaries grafted to either orthotopic (returned to normal position) or heterotopic (alternative positions) sites, but there have not been any studies directly comparing oocyte quality or yield between the different graft sites. Orthotopic grafts permit natural conception and circumvent the need for in vitro maturation (IVM) and/or in vitro fertilization (IVF) that is required for heterotopic grafts (Jones \& Krohn 1960, Gosden et al. 1994, Cox et al. 1996, Petroianu et al. 2002, Almodin et al. 2004a, b, Donnez et al. 2004). However, most clinical studies to date have placed ovarian grafts under the 
skin to permit easy monitoring of follicle growth and provide ready access to the graft for oocyte collection (Oktay \& Yih 2002, Oktay et al. 2003, 2004).

Heterotopic ovarian grafts placed under the kidney capsule of mice yield viable oocytes that can develop after fertilization to term when placed in gestational surrogates (Carroll et al. 1990, Waterhouse et al. 2004). The only report of a live young derived from a subcutaneously located graft occurred in a monkey when the resulting embryos were transferred to a gestational surrogate (Lee et al. 2004). Oocytes collected from human ovarian tissue grafted under the skin of the forearm have proved difficult to successfully fertilize and establish a pregnancy (Oktay et al. 2003). A four-cell embryo was produced from one woman by intracytoplasmic sperm injection from oocytes harvested from ovarian tissue grafted subcutaneously to the abdominal wall. However, this four-cell embryo failed to implant following transfer into the patient's uterus (Oktay et al. 2004).

In experimental animal models, the pregnancy rates of recipients of fresh or frozen ovarian orthotopic grafts tend to be lower than for non-grafted controls (Cox et al. 1996, Candy et al. 2000, Shaw et al. 2000, Wang et al. 2002a, Almodin et al. 2004a) and has been attributed to reduced follicle numbers and adhesions rather than reduced oocyte quality. However, studies on sheep indicate that oocyte quality may be compromised generally in ovarian grafts (Gosden et al. 1994, Aubard et al. 1999,, Salle et al. 2002, 2003). If proven to be correct, this could be a concern for clinical application of grafting cryopreserved ovarian tissue. Sheep oocytes usually develop well in vitro, but oocytes collected from subcutaneous grafts appear to have compromised developmental potential as none developed beyond the four-cell stage (Aubard et al. 1999). Another study found a very high death rate $(50 \%)$ among male lambs born following spontaneous conception to sheep with ovarian orthotopic grafts (Salle et al. 2002, 2003). However it has not yet been established whether these deaths could be attributed to ovarian grafting or to other unrelated factors such as the choice of ram used.

If oocytes are to be collected from ovarian grafts for IVF, it will be important to maximize the graft yield of normal, mature oocytes. The number that can be collected will depend not only on how long the grafts remain functional but also on whether follicle growth and oocyte maturation can be stimulated with exogenous gonadotrophins. Ovarian grafts in mice can function for one year (Candy et al. 2000, Shaw et al. 2000) and grafts in sheep have been reported to function for up to two years (Baird et al. 1999). Ovarian grafts in humans may cease to function after a single menstrual cycle (Radford et al. 2001) or remain functional for a year or more (Oktay et al. 2001, Oktay \& Yih 2002, Donnez et al. 2004, Meirow et al. 2005, Siegel-Itzkovich 2005). In mice with ovarian grafts under the kidney capsule, administration of gonadotrophins does not significantly increase the oocyte yield (Carroll et al. 1990, Waterhouse et al. 2004). The effect of gonadotropins on subcutaneous grafts in mice is not known. Stimulation with exogenous gonadotrophins has been used for patients with ovarian grafts to in an attempt to enhance the likelihood of obtaining mature oocytes (Oktay \& Yih 2002), but whether this influences oocyte yield or quality is not known.

The present study investigates the ability of mouse oocytes collected from orthotopic and heterotopic sites to produce embryos, fetuses and live young with and without gonadotrophin stimulation.

\section{Materials and Methods Animals}

Ethical approval for these studies was obtained from the Monash University Department of Physiology Animal Ethics Committee and complied with the conditions laid down by the NH\&MRC/CSIRO/AAC Australian Code of Practice for the Care and Use of Animals for Scientific Purposes (1997). Four week old female F1 hybrid $(\mathrm{C} 57 \mathrm{BL} \times \mathrm{CBA})$ mice were used as both ovarian tissue donors and graft recipients $(n=103)$. Female mice of the same F1 hybrid strain were used as controls for the collection of germinal vesicle (GV) oocytes for IVM $(n=8)$ and in vivo matured (ovulated) oocytes $(n=14)$. The sperm donors were 10-12 week old male mice of the same F1 hybrid strain as the ovarian donors $(n=10)$. The pseudopregnant surrogate mothers were 2-3 month old F1 hybrid mice of the same strain $(n=14)$ made pseudopregnant by mating to proven vasectomised males. All mice were obtained from Monash University Central Animal Services. All mice were housed under a $12 \mathrm{~h}$ light: $12 \mathrm{~h}$ darkness regimen at $21^{\circ} \mathrm{C}$ in the Department of Physiology Animal House.

\section{Ovarian transplantation procedure}

Each female mouse acted as both ovarian tissue donor and graft recipient in order to minimize animal usage. Ovarian grafting was performed using standard procedures (Cox et al. 1996, Shaw et al. 2000, Cleary et al. 2003). Briefly, pairs of female mice were simultaneously anaesthetised by administering each with $0.2 \mathrm{ml}$ i.p. injection containing $1 \mathrm{mg} / \mathrm{ml}$ xylazine hydrochloride (Ilium Xylazil20; Troy Laboratories, Smithtown, Australia) and $5 \mathrm{mg} / \mathrm{ml}$ ketamine hydrochloride (Ketamine; Parnell Laboratories, Alexandria, Australia). Once anaesthetized, the dorsal skin of both mice was swabbed with $70 \%(\mathrm{v} / \mathrm{v})$ alcohol, a $1 \mathrm{~cm}$ dorsal incision was made through the skin and bilateral ovariectomy was performed on each mouse. The excised ovaries were placed in Dulbecco's phosphate-buffered saline (PBS; Gibco BRL, Gaithersburg, USA) and were cut in half before being grafted. Recipients received either two hemi-ovarian grafts under each kidney capsule, or four hemi-ovarian grafts placed subcutaneously onto the back of the mouse, or one hemi-ovarian graft into 
each bursal cavity. To facilitate identification of the subcutaneous grafts, the graft sites were marked with 1-0 silk suture. The skin was closed with $9 \mathrm{~mm}$ Michel clips (Clay Adams, Sparks, USA).

\section{Gonadotrophin stimulation protocol}

In the third week after grafting, the graft recipients in the hormone treatment group were all treated with $5 \mathrm{IU}$ pregnant mare serum gonadotrophin (PMSG; Folligon; Intervet, Castle Hill, Australia) and 5 IU hCG (Chorulon, Intervet, Castle Hill, Australia) $48 \mathrm{~h}$ later and were killed on day $21,10 \mathrm{~h}$ after the hCG injection. Age matched intact female controls were superovulated with the same dose of PMSG and hCG.

\section{In vitro culture}

The graft recipients were killed three weeks after grafting because in mice primordial follicles take three weeks to reach the preovulatory stage (Cox et al. 2000). Mice that were stimulated with gonadotrophins were killed $10 \mathrm{~h}$ after the hCG injection to avoid ovulation of oocytes from the graft. The mice were killed by cervical dislocation and the grafts were collected into equilibrated $\left(5 \% \mathrm{CO}_{2}\right.$ at $\left.37^{\circ} \mathrm{C}\right)$ minimum essential medium alpha (MEM $\alpha$; Sigma), supplemented with $10 \%$ fetal calf serum (FCS, Gibco) under mineral oil (Sigma). The number of grafts retrieved was noted. The oocytes were released by puncturing large antral follicles with a 26G needle and the oocytes collected. Oocytes were then moved into fresh equilibrated MEM $\alpha$ maturation media supplemented with $10 \% \mathrm{v} / \mathrm{v}$ FCS, $1 \mathrm{IU} / \mathrm{ml}$ PMSG, $1 \mathrm{IU} / \mathrm{ml}$ hCG and $1 \mathrm{ng} / \mathrm{ml}$ EGF (Sigma). The maturity and number of oocytes collected per graft was noted. Oocytes with compact cumulus cells and germinal vesicles (GV) were cultured at $37^{\circ} \mathrm{C}$ with $5 \% \mathrm{CO}_{2}$ for 16 $18 \mathrm{~h}$ before being fertilized in vitro. Oocytes with an expanded cumulus were fertilized in vitro approximately $2 \mathrm{~h}$ after oocyte collection. IVF was performed in equilibrated mT6 medium using sperm capacitated in $\mathrm{mT} 6$ for $1 \mathrm{~h}$. Oocytes were left with sperm in the fertilization medium for $2 \mathrm{~h}$ and were washed before being moved to equilibrated KSOMaa embryo culture medium (Ho et al. 1995) at $37^{\circ} \mathrm{C}$ with $5 \% \mathrm{CO}_{2}$ for $24 \mathrm{~h}$. The number of two-cell embryos produced was scored at this time.

GV oocytes collected from intact F1 females the same age as the recipients served as an IVM control. The GV oocytes were collected from the non-stimulated female controls and then matured and fertilized in vitro under the same conditions as oocytes retrieved from grafts (see above). In vivo matured oocytes collected from oviducts of intact superovulated F1 females were used as a second control group. In these controls the ovulated oocytes were collected $14 \mathrm{~h}$ after the hCG injection to allow insemination at the same time as the oocytes from the ovarian grafts. All culture and handling procedures were identical to those described for the grafted group.

\section{Embryo transfer}

Adult female F1 hybrid mice were placed with vasectomised males of the same strain. Females were examined for evidence of a vaginal plug. On the day of finding a vaginal plug, the two-cell embryos were transferred to the oviducts. Recipients were anaesthetised as described above. Each oviduct was located and exteriorised and the embryos (up to 6 per uterine horn) were inserted into the opening of the oviduct using a thin glass pipette. The reproductive tract was returned to its original position and the skin was closed with Michel clips. Females that were to be allowed to progress to term had embryos belonging to a single treatment group transferred to both oviducts. Females which were to be examined on day 15 of gestation had a different treatment group transferred to the two oviducts to control for between female variations.

\section{Assessment of day 15 fetuses and live-born pups}

Recipients which were killed on day 15 of gestation, had the implantation sites counted and the health of the fetuses assessed. The weight of each fetus and its placenta was recorded. Those fetuses that were allowed to develop to term had their health monitored until the time of weaning. The surrogate mothers were killed by cervical dislocation at the time of weaning, their uteri were dissected out and the number of implantation sites were counted and compared with the number of pups to determine how many embryos were lost during the pregnancy. Live born pups were either killed by cervical dislocation at four weeks of age or were kept and then mated with their siblings from the same litter for fertility testing.

\section{Statistical analyses}

In each treatment group, data were pooled and chi-square tests were used to statistically analyse graft recovery, number of two-cell embryos, implantation sites and fetuses between groups. The number of oocytes collected was expressed as the mean \pm S.E.M. per ovary (equivalent of two hemi-ovarian grafts). The fetal and placental weights were expressed as mean \pm S.E.M. One way ANOVA was used for statistical analysis of the number of oocytes and fetal and placental weights between the treatment groups. Results were considered significant when $P=0.05$. All statistical analysis was carried out using the computer statistical package SPSS11.0 (SPSS Inc., Chicago, USA).

\section{Results}

\section{Graft recovery}

Ovarian grafts were successfully recovered from all graft sites in both the non-stimulated and the gonadotrophintreated groups. There was no significant difference in the recovery rates from the same graft site between these two groups. However, graft recovery rate was significantly 
$(P<0.001)$ less at the subcutaneous graft site with only $56-58 \%$ of the grafts recovered compared with the bursal cavity and kidney capsule which had 98-100\% and 93$95 \%$ of the grafts retrieved respectively (Table 1 ). When the graft was not clearly visible, the graft site was searched carefully under high power magnification for any evidence of ovarian remnants.

\section{Oocyte recovery}

Ovarian grafts from all graft sites, with and without gonadotrophin stimulation, had evidence of antral follicle development. Overall, ovarian grafts gave a significantly lower yield of oocytes per ovary compared with GV oocyte controls and the superovulated intact controls $(22.25 \pm 7.7$ and $16.3 \pm 2.2$ respectively; Fig. 1). Graft recipients that received no gonadotrophin, had similar oocyte yields for the bursal cavity and kidney capsule (10.1 \pm 1.2 and $11.9 \pm 1.7$, respectively). Subcutaneously placed ovaries had a significantly lower oocyte yield ( $2.0 \pm 0.2$ oocytes per ovary) than those placed under the kidney capsule or in the bursal cavity. All collected oocytes, regardless of graft site, were at the GV stage of development.

Grafts that were stimulated with exogenous gonadotrophins had the following number of oocytes recovered: bursal cavity, $8.6 \pm 1.0$; kidney capsule, $6.5 \pm 0.9$; and subcutaneous, $2.1 \pm 0.3$. Significantly fewer oocytes were retrieved from grafts to the kidney capsule $(P<0.05)$ than to the bursa following gonadotrophin stimulation. Both the kidney and bursal sites yielded significantly more oocytes than the subcutaneous site. After exposure to exogenous gonadotrophins, mature metaphase II (MII) oocytes as well as immature GV oocytes, were retrieved from grafts at all sites (bursal cavity: $37 \%$ GV oocytes and 63\% MII oocytes; kidney capsule: 30\% GV oocytes and $70 \%$ MII oocytes; subcutaneous: 26\% GV oocytes and $74 \%$ MII oocytes).

The number of oocytes recovered did not increase significantly after treatment with exogenous gonadotrophins. Both the bursal cavity and subcutaneous graft sites had similar numbers of oocytes at collection regardless of whether they were exposed to gonadotrophins. Grafts from under the kidney capsule, however, had significantly fewer oocytes collected from the gonadotrophin stimulated group compared with the groups that were not treated with exogenous gonadotrophins (Fig. 1).

\section{Two-cell cleavage rate}

The two-cell cleavage rate of in vitro matured GV oocytes collected from non-stimulated grafts was significantly higher for the orthotopic group (bursal cavity, 36\%) than for both of the heterotopic graft sites. The cleavage rate for

Table 1 The number of ovarian grafts retrieved three weeks after grafting and the number of half ovaries grafted to each of the three graft sites, for the non-stimulated group and the group treated with exogenous hormones (PMSG and hCG).

\begin{tabular}{lccrc}
\hline & \multicolumn{2}{c}{ No hormone } & \multicolumn{2}{c}{ PMGS \& hCC } \\
\cline { 2 - 5 } Graft groups & $n$ mice & $n$ retrieved $/ n$ grafted $(\%)$ & $n$ retrieved $/ n$ grafted $(\%)$ \\
\hline Bursal cavity & 22 & $43 / 44(98)^{\mathrm{a}}$ & $22 / 22(100)^{\mathrm{a}}$ \\
Kidney capsule & 13 & $48 / 52(93)^{\mathrm{a}}$ & 6 & $19 / 20(95)^{\mathrm{a}}$ \\
Subcutaneous & 29 & $65 / 116(56)^{\mathrm{b}}$ & 24 & $56 / 96(58)^{\mathrm{b}}$ \\
\hline
\end{tabular}

The same superscript letters indicates groups that are statistically the same $(P<0.05)$.

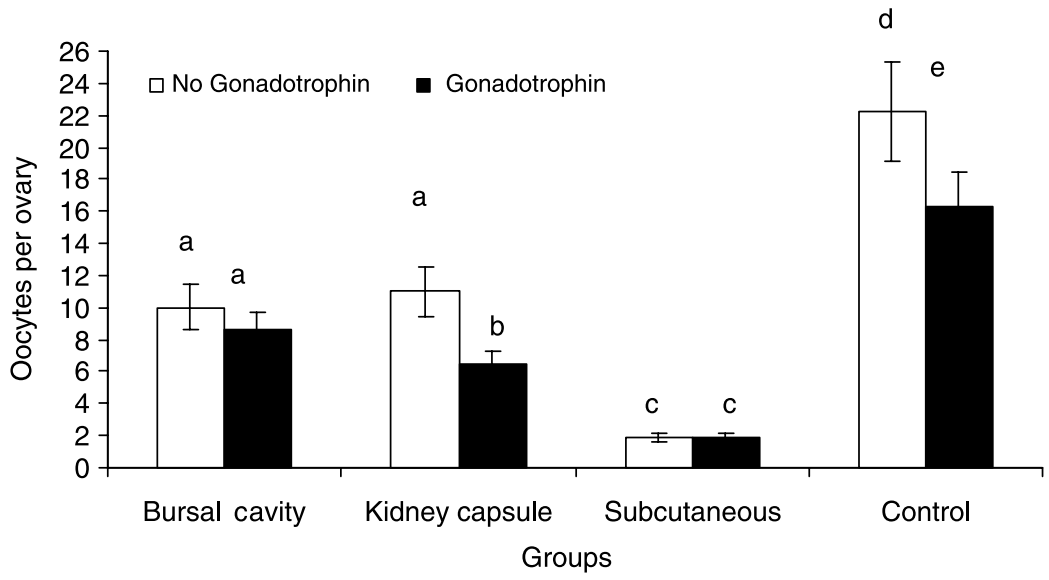

Figure 1 The mean \pm S.E.M. number of oocytes recovered with and without exogenous hormone stimulation per ovary. The same superscript letter indicates that the groups were statistically the same, $P<0.05$. NOTE: The ovaries were cut in half prior to grafting. 
the two heterotopic sites was not significantly different (kidney capsule, 19\% and subcutaneous, 16\%; Fig. 2).

GV oocytes from the bursal cavity and kidney capsule of gonadotrophin treated recipients had a higher cleavage rate after IVM and IVF (60\% and 56\%, respectively) than the oocytes from the subcutaneous graft site (7\%; Fig. 2). There was no significant difference in the cleavage rates of MII eggs between the three grafts sites (bursal cavity 55\%, kidney capsule $42 \%$, subcutaneous $49 \%$ ). There was no significant difference in the cleavage rate between GV and MII eggs from the bursal cavity and kidney capsule graft sites. At the subcutaneous graft site, however, there was a significantly lower cleavage rate for GV oocytes compared with MII eggs retrieved from the same grafts site.

The recipients in the gonadotrophin-treated group of the bursal cavity and kidney capsule graft sites had significantly higher cleavage to two-cells when compared with the non-treated group. At the subcutaneous graft site however, only the MII eggs of the gonadotrophin-treated group had a significantly better cleavage rate when compared with the non-treated group, GV oocytes had comparable cleavage rates. Oocytes in grafts at all graft sites in both the stimulated and non-stimulated treatment groups had significantly lower development to two-cells than both the in vitro and in vivo matured oocytes from the control ovaries $(78 \%$ and $86 \%$ cleavage, $P<0.05$; Fig. 2$)$.

\section{Fetuses and live born pups}

The fetuses collected 15 days after the transfer of two-cell embryos were phenotypically normal in the non-stimulated group for all graft sites. There was no significant difference in the proportion of two-cell embryos that implanted or formed fetuses for the three different graft sites (Table 2). There was no significant difference in the implantation rate between the grafted groups and the controls but fewer embryos from grafts formed fetuses.

There was no statistical difference in the development to fetuses for oocytes collected from the kidney capsule graft site in the stimulated and non-stimulated group. However, at the bursal cavity graft site, oocytes from stimulated grafts that were fertilized had a significantly higher fetal development rate when compared with oocytes from non-stimulated grafts. There was no significant difference in the implantation and fetal development rates between graft groups and the control group for twocell embryos derived from gonadotrophin stimulated graft recipients.

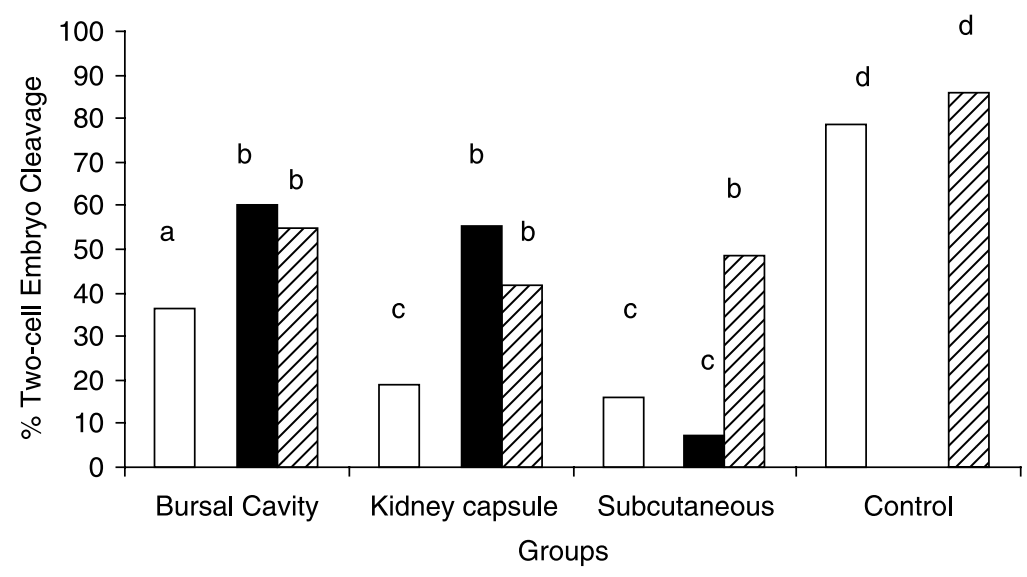

$\square$ GV No Gonadotrophin $\triangle$ MII No Gonadotrophin $\square$ GV Gonadotrophin $\square$ MII Gonadotrophin

Figure 2 The percentage of two-cell embryos after IVM and/or IVF. Note: Percentages are expressed as total two-cell embryos per total oocytes from GV or MII oocyte origin. The same superscript indicates groups that are statistically the same, $P<0.05$.

Table 2 Number $(n)$ of two-cell embryos transferred, the proportion that implanted and developed into fetuses at day 15 of gestation.

\begin{tabular}{|c|c|c|c|c|c|c|}
\hline \multirow[b]{2}{*}{ Graft groups } & \multicolumn{3}{|c|}{ No hormone } & \multicolumn{3}{|c|}{ Hormone } \\
\hline & $n$ transferred & $n$ implanted* (\%) & $n$ fetuses* $(\%)$ & $n$ transferred & $n$ implanted* (\%) & $n$ fetuses* $(\%)$ \\
\hline Bursal cavity & 17 & $11(65)$ & $4\left(24^{\mathrm{a}}\right)$ & 4 & $4(100)$ & $4\left(100^{b}\right)$ \\
\hline Kidney capsule & 19 & $10(53)$ & $7\left(37^{a}\right)$ & 3 & $3(100)$ & $2\left(67^{a, b}\right)$ \\
\hline Subcutaneous & 10 & $7(70)$ & $2\left(20^{\mathrm{a}}\right)$ & NT & NT & NT \\
\hline Control & & N/A & & 67 & $50(75)$ & $39\left(58^{b}\right)$ \\
\hline
\end{tabular}

* Percentages are expressed as $n$ implanted/ $n$ transferred and $n$ fetuses/ $n$ transferred. NT, not transferred; N/A, not applicable; controls were treated with gonadotrophins. The same superscript letters in the same row or column indicates groups that are statistically the same, $P \leq 0.01$. 
Overall, irrespective of the graft site or hormone treatment, the fetal and placental weights of the fetuses did not differ significantly from the control group, with the exception of the subcutaneous fetuses from the nonstimulated treatment group, which had a significantly lower fetal weight $(P<0.05$; Table 3$)$.

When surrogate mothers were allowed to carry the fetuses to term, healthy pups were born from oocytes retrieved from grafts to the bursal cavity $(n=14)$ and kidney capsule $(n=3)$ of non-stimulated graft recipients. Embryos obtained from gonadotrophin stimulated recipients with subcutaneous grafts formed four live-born pups after embryo transfer. All pups developed normally while under observation up to the weaning age. Ten pups were mated with their siblings and normal sized litters of apparently normal pups were born indicating that they were fertile.

\section{Discussion}

This study compares the developmental potential of oocytes from ovaries grafted to the bursal cavity, kidney capsule and subcutaneous tissue sites. It was also demonstrated that ovarian grafts at orthotopic and heterotopic sites can produce viable oocytes, that are capable of developing into fetuses and live young. However, the oocytes from ovarian grafts differed from those collected from ungrafted ovaries. Oocytes collected from ovarian grafts, irrespective of the position of the graft site have significantly lower two-cell embryo cleavage rates after IVF. This confirms previous studies where low numbers of embryos produced from orthotopic (Aubard et al. 1999, Oktay \& Yih 2002) and heterotopic grafts were reported (Aubard et al. 1999, Snow et al. 2002, Lee et al. 2004, Oktay et al. 2004, Waterhouse et al. 2004). Collectively this indicates that further work is required to determine why oocytes that develop in ovarian grafts have reduced developmental competence.

Oocytes collected from ovarian grafts appear to have a reduced developmental potential in comparison to the

Table 3 Fetal and placental weights at day 15 of gestation.

\begin{tabular}{|c|c|c|c|c|}
\hline \multirow[b]{2}{*}{ Graft groups } & \multicolumn{2}{|c|}{ No hormone } & \multicolumn{2}{|c|}{ Hormone } \\
\hline & $\begin{array}{l}\text { Fetal wt } \\
(\mathrm{mg})\end{array}$ & $\begin{array}{l}\text { Placental wt } \\
\quad(\mathrm{mg})\end{array}$ & $\begin{array}{l}\text { Fetal wt } \\
(\mathrm{mg})\end{array}$ & $\begin{array}{l}\text { Placental wt } \\
\quad(\mathrm{mg})\end{array}$ \\
\hline Bursal cavity & $\begin{array}{c}249 \pm 10 \\
n=4\end{array}$ & $107 \pm 5$ & $\begin{array}{c}266 \pm 18 \\
n=4\end{array}$ & $111 \pm 17$ \\
\hline Kidney capsule & $\begin{array}{c}256 \pm 13 \\
n=4\end{array}$ & $118 \pm 7$ & $\begin{array}{c}268 \pm 16 \\
n=4\end{array}$ & $111 \pm 21$ \\
\hline Subcutaneous & $\begin{array}{c}176 \pm 36 * \\
n=2\end{array}$ & $107 \pm 16$ & NT & NT \\
\hline Control & \multicolumn{2}{|c|}{ N/A } & $\begin{array}{c}238 \pm 6 \\
n=39\end{array}$ & $104 \pm 3$ \\
\hline
\end{tabular}

* Indicates groups that are statistically different for that variable, $P<0.05$. NT, not transferred; N/A, not applicable, controls were treated with gonadotrophins. Data are means \pm S.E.M. oocytes produced in situ. The grafting process causes ischemic-reperfusion injury that occurs as the graft establishes a new blood supply. This period of poor vascular support may adversely affect the oocyte and growing follicles. Damage to the perivascular and endothelial cells has been shown to have an influence on the integrity of ovarian follicles and oocytes in ovarian grafts (Israely et al. 2003). Ovarian grafting also disrupts innervation of the ovary. The ovary is innervated by extrinsic and intrinsic nerves that are believed to control blood flow, as well as follicle and oocyte development (Dissen et al. 1995, D'Albora et al. 2000, 2002, Anesetti et al. 2001, Aguado 2002). Normal follicle development and the production of viable oocytes is a complicated process that involves coordination of numerous molecules including hormones, growth factors and receptors, in various signalling pathways that act in autocrine, paracrine and endocrine manners (Yamashita et al. 2000, Josefsberg \& Dekel 2002, Matzuk \& Lamb 2002, Drummond et al. 2003). Although grafted ovaries do become re-vascularized and re-innervated, the grafting process may perturb the systems that are essential for normal follicle growth and oocyte development and thus result in a reduced number of developmentally competent oocytes.

In addition, embryos produced from oocytes collected from grafts have significantly lower capacity to develop to fetuses when compared with intact ovaries, even though the implantation rates are comparable. This was due to the higher reabsorption rates from embryos of graft origin. The lower quality of oocytes produced from ovarian grafts may account for the high embryonic reabsorption rate as the quality of the oocyte is a primary determinant of embryo quality (Gosden 2002). Despite this, the fertilized oocytes that completed development formed phenotypically normal fetuses and pups which developed into normally fertile adults. This shows that at least some oocytes retrieved from ovarian grafts are developmentally viable.

The position of the graft influenced graft recovery and the number of oocytes retrieved. The bursal cavity and kidney capsule yielded more grafts and oocytes than the subcutaneous graft site. This is comparable to previous reports (Cleary et al. 2003, Hernandez-Fonseca et al. 2004, Waterhouse et al. 2004). The bursal cavity and kidney capsule graft site have a relatively good blood supply that facilitates the revascularization process which is essential for graft establishment and the support of follicular growth. The main cause for graft and follicle loss in the process of ovarian transplantation is believed to be posttransplant ischaemia. In mice, transplantation accounts for approximately $42 \%$ of the loss in follicle population while cryopreservation reduces the loss of follicles by a further $9 \%$ (Liu et al. 2002). This substantial loss of follicles is also observed in larger animal models (Baird et al. 1999). The duration of the ischaemia prior to revascularization of transplanted ovarian tissue depends on several factors, such as the size of the tissue, the graft site and the 
presence of angiogenic factors. Rodent ovaries are relatively small and re-vascularize within $24-48 \mathrm{~h}$ of grafting (Dissen et al. 1994). Israely et al. (2003) reported that subcutaneous grafts have a poor blood supply and altered vascular integrity. Loss and damage of perivascular and endothelial cells was closely correlated with loss of follicular and oocyte integrity. Thus in this present study, an altered vascular supply may not have provided sufficient support (e.g. hormonal) for the ovarian grafts and follicles at the subcutaneous site. This could be why so many of the subcutaneous grafts failed to become established.

Although it is not clear from this study why orthotopic grafts produce better oocytes than heterotopic grafts, a plausible reason is that oocytes from grafts in heterotopic groups are deprived of local factors from the uterus or orthotopic site that are required for normal follicle and oocyte development. Furthermore, transplantation of ovarian tissue to other sites within the body may disrupt some ovarian processes and/or expose the ovary to a different environment. The renin-angiotensin system in the kidney regulates systemic blood pressure and fluid homeostasis. There are data supporting the idea that the reninangiotensin system also exerts an influence in the ovary playing a role in follicular development, steroidogenesis, oocyte maturation, ovulation and follicle atresia (Yoshimura 1997, Li et al. 2004), and that this system is regulated by gonadotrophins (Kuji et al. 1996). It is, therefore, possible that the renal renin-angiotensin system affects follicle development and oocyte maturation in ovarian grafts placed on the kidney.

Alternatively, physical changes may interrupt follicle/ oocyte competence in ovarian grafts. Donnez et al. (2004) suggested that because subcutaneous ovarian grafts, are placed close to the body surface, they may experience changes in temperature and pressure that could damage oocytes. Decreasing or increasing the temperature of oocytes results in damage to the cytoskeleton and meiotic spindle (Liu et al. 2003, Payton et al. 2004, Sun et al. 2004a,b).

Hormonal feedback between the pituitary and ovary regulates oocyte development and may be disturbed by grafting and in particular grafting to heterotopic sites. Although endocrine function was not monitored in this study, ovarian grafting in sheep results in perturbations in hormone levels. The secretion of inhibin A in ovarian grafts is decreased which in turn causes a rise in FSH concentrations and may result from the reduced number of preantral follicles in ovarian grafts. $\mathrm{LH}$ concentrations are also elevated in sheep with ovarian grafts, however progesterone and oestrogen levels are normal throughout the cycle (Baird et al. 2004). Whereas in rats, oestrogen and cyclic activity are altered in heterotopic ovarian grafts (Petroianu et al. 2005). Abnormalities in hormonal concentrations may alter follicle development. There is evidence that in the grafts in mice and sheep, both the rate of recruitment and the rate of follicle development are accelerated following grafting (Cox et al. 2000, Baird et al.
2004). This indicates that abnormalities in ovarian function within ovarian grafts may be due to an altered endocrine environment within ovarian graft recipients. This may account for the poor follicle response and reduced developmental competence of oocytes within ovarian grafts observed in this study.

Treatment of the graft recipients with the standard mouse superovulation protocol did not significantly increase the number of oocytes at any of the three graft sites. Previous studies where exogenous PMSG was administered to stimulate ovarian tissue grafted under the kidney capsule also failed to increase the yield of oocytes from ovarian grafts (Snow et al. 2002, Waterhouse et al. 2004). Collectively, data from this study and previous studies indicate that developing follicles in ovarian grafts, irrespective of the graft site, do not respond to exogenous gonadotrophins in the same manner as intact ovaries. The reason for this is not known, but it may be possible that the vascular remodelling that occurs in the ovarian graft does not allow adequate delivery of the gonadotrophin to the grafts. It may also be possible that the altered response may be due to low numbers of follicles in the ovarian grafts, as studies have shown that women with small ovarian reserves have a lower response rate to ovarian stimulation with gonadotrophins (El-Toukhy et al. 2002, Younis et al. 2005).

Mature MIl eggs were retrieved from the ovaries of gonadotrophin-treated recipients at all three graft sites. The cumulus cells surrounding the oocytes were expanded and had the same morphology as the ovulated eggs from the control group. The mucification process is known to occur before ovulation and is triggered by gonadotrophins, which induce the production and secretion of hyaluronic acid from the cumulus cells (Eppig 1979). The MIl oocytes had extruded the first polar body (data not shown) and could be fertilized without IVM. Waterhouse et al. (2004) and Carroll et al. (1990) collected oocytes from ovarian grafts on the kidney $12 \mathrm{~h}$ after hCG injection, but the majority of the oocytes retrieved from their studies were GV oocytes and required IVM before fertilization. In the mouse, it is believed that the extrusion of the first polar body occurs in vivo from $10 \mathrm{~h}$ onwards after hCG injection (Nagy et al. 2003). The ability of the oocytes in the grafts to undergo mucification and first polar body extrusion indicates that some exogenous hormones reached the follicles and produced an effect on the ovarian grafts.

Gonadotrophin treatment of graft recipients improved the embryo development of fertilized oocytes. Both GV oocytes and MII oocytes collected from ovarian grafts stimulated with exogenous hormones had a higher cleavage rate than the unstimulated group. This was previously reported by Waterhouse et al. (2004) who also observed a significantly higher rate of two-cell embryos after PMSG and hCG treatment of graft recipients when compared with unstimulated graft recipients. However these rates of 
development were still lower than the in vitro and in vivo controls as observed in the present study.

Embryos that arose from gonadotrophin-treated grafts (irrespective of graft site) had comparable rates of implantation and fetal development when compared with the control group. However, only a small number of embryos were transferred. Some embryos that were transferred did not implant and some surrogate mothers did not become pregnant (data not shown). It is not known whether it is because the quality of the embryos was reduced or whether the surrogate mothers were unable to sustain the pregnancy. The weights of the fetus and placenta are comparable across all groups, the only exception was the subcutaneous group, where the fetal weight was significantly lower (the placental weight was normal). However, only two fetuses developed in this group and definitive conclusions are not possible with the small sample size.

This study demonstrated that viable oocytes, capable of developing into normal fetuses and live young, can be collected from orthotopic and heterotopic ovarian grafts. However, significantly more developmentally competent oocytes are produced from orthotopic grafts than heterotopic grafts. Thus, graft site is an important consideration for the production of developmentally competent oocytes from ovarian grafts. Stimulation of ovarian grafts with exogenous gonadotrophin induces meiotic maturation in oocytes within ovarian grafts but it does not increase oocyte yield.

\section{Funding}

This study was supported by grants from ARC, NIH, Monash IVF. The authors declare that there is no conflict of interest that would prejudice the impartiality of this scientific work.

\section{References}

Aguado LI 2002 Role of the central and peripheral nervous system in the ovarian function. Microscopy Research and Technique 59 $462-473$.

Almodin CG, Minguetti-Camara VC, Meister H, Ceschin AP, Kriger E \& Ferreira JO 2004a Recovery of natural fertility after grafting of cryopreserved germinative tissue in ewes subjected to radiotherapy. Fertility and Sterility 81 160-164.

Almodin CG, Minguetti-Camara VC, Meister H, Ferreira JO, Franco RL, Cavalcante AA, Radaelli MR, Bahls AS, Moron AF \& Murta CG 2004b Recovery of fertility after grafting of cryopreserved germinative tissue in female rabbits following radiotherapy. Human Reproduction 19 1287-1293.

Anesetti G, Lombide P, D'Albora H \& Ojeda SR 2001 Intrinsic neurons in the human ovary. Cell and Tissue Research 306 231-237.

Aubard Y, Piver P, Cogni Y, Fermeaux V, Poulin N \& Driancourt MA 1999 Orthotopic and heterotopic autografts of frozen-thawed ovarian cortex in sheep. Human Reproduction 14 2149-2154.

Baird DT, Webb R, Campbell BK, Harkness LM \& Gosden RG 1999 Long-term ovarian function in sheep after ovariectomy and transplantation of autografts stored at $-196^{\circ}$ C. Endocrinology 140 $462-471$.
Baird DT, Campbell B, de Souza C \& Telfer E 2004 Long-term ovarian function in sheep after ovariectomy and autotransplantation of cryopreserved cortical strips. European Journal of Obstetrics, Gynecology, and Reproductive Biology 113 (Suppl 1) S55-S59.

Candy CJ, Wood MJ \& Whittingham DG 2000 Restoration of a normal reproductive lifespan after grafting of cryopreserved mouse ovaries. Human Reproduction 15 1300-1304.

Carroll J, Whittingham DG, Wood MJ, Telfer E \& Gosden RG 1990 Extra-ovarian production of mature viable mouse oocytes from frozen primary follicles. Journal of Reproduction and Fertility 90 $321-327$.

Cleary M, Paris MC, Shaw J, Jenkin G \& Trounson A 2003 Effect of ovariectomy and graft position on cryopreserved common wombat (Vombatus ursinus) ovarian tissue following xenografting to nude mice. Reproduction, Fertility, and Development 15333 -342.

Cox S, Shaw J \& Jenkin G 2000 Follicular development in transplanted fetal and neonatal mouse ovaries is influenced by the gonadal status of the adult recipient. Fertility and Sterility 74 366-371.

Cox SL, Shaw J \& Jenkin G 1996 Transplantation of cryopreserved fetal ovarian tissue to adult recipients in mice. Journal of Reproduction and Fertility 107 315-322.

D'Albora H, Lombide P \& Ojeda SR 2000 Intrinsic neurons in the rat ovary: an immunohistochemical study. Cell and Tissue Research $30047-56$

D'Albora H, Anesetti G, Lombide P, Dees WL \& Ojeda SR 2002 Intrinsic neurons in the mammalian ovary. Microscopy Research and Technique 59 484-489.

Dissen GA, Lara HE, Fahrenbach WH, Costa ME \& Ojeda SR 1994 Immature rat ovaries become revascularized rapidly after autotransplantation and show a gonadotropin-dependent increase in angiogenic factor gene expression. Endocrinology 134 1146-1154.

Dissen GA, Hirshfield AN, Malamed S \& Ojeda SR 1995 Expression of neurotrophins and their receptors in the mammalian ovary is developmentally regulated: changes at the time of folliculogenesis. Endocrinology $1364681-4692$.

Donnez J, Dolmans MM, Demylle D, Jadoul P, Pirard C, Squifflet J, Martinez-Madrid B \& van Langendonckt A 2004 Livebirth after orthotopic transplantation of cryopreserved ovarian tissue. Lancet $3641405-1410$.

Drummond AE, Dyson M, Le MT, Ethier JF \& Findlay JK 2003 Ovarian follicle populations of the rat express TGF-beta signalling pathways. Molecular and Cellular Endocrinology 202 53-57.

El-Toukhy T, Khalaf Y, Hart R, Taylor A \& Braude P 2002 Young age does not protect against the adverse effects of reduced ovarian reserve-an eight year study. Human Reproduction 17 1519-1524.

Eppig JJ 1979 FSH stimulates hyaluronic acid synthesis by oocytecumulus cell complexes from mouse preovulatory follicles. Nature $281483-484$.

Gosden RG 2002 Oogenesis as a foundation for embryogenesis. Molecular and Cellular Endocrinology 186 149-153.

Gosden RG, Baird DT, Wade JC \& Webb R 1994 Restoration of fertility to oophorectomized sheep by ovarian autografts stored at -196 degrees C. Human Reproduction 9 597-603.

Hernandez-Fonseca H, Bosch P, Sirisathien S, Wininger JD, Massey JB \& Brackett BG 2004 Effect of site of transplantation on follicular development of human ovarian tissue transplanted into intact or castrated immunodeficient mice. Fertility and Sterility $\mathbf{8 1}$ Suppl $1888-892$

Ho Y, Wigglesworth K, Eppig JJ \& Schultz RM 1995 Preimplantation development of mouse embryos in KSOM: augmentation by amino acids and analysis of gene expression. Molecular Reproduction and Development 41 232-238.

Israely T, Dafni H, Granot D, Nevo N, Tsafriri A \& Neeman M 2003 Vascular remodeling and angiogenesis in ectopic ovarian transplants: a crucial role of pericytes and vascular smooth muscle cells in maintenance of ovarian grafts. Biology of Reproduction 68 2055-2064.

Jones EC \& Krohn PL 1960 Orthotopic ovarian transplantation in mice. Journal of Endocrinology 20 135-146. 
Josefsberg LB \& Dekel N 2002 Translational and post-translational modifications in meiosis of the mammalian oocyte. Molecular and Cellular Endocrinology 187 161-171.

Kuji N, Sueoka K, Miyazaki T, Tanaka M, Oda T, Kobayashi T \& Yoshimura Y 1996 Involvement of angiotensin II in the process of gonadotropin-induced ovulation in rabbits. Biology of Reproduction 55 984-991.

Lee DM, Yeoman RR, Battaglia DE, Stouffer RL, Zelinski-Wooten MB, Fanton JW \& Wolf DP 2004 Live birth after ovarian tissue transplant. Nature 428 137-138.

Liu J, Van der Elst J, Van den Broecke R \& Dhont M 2002 Early massive follicle loss and apoptosis in heterotopically grafted newborn mouse ovaries. Human Reproduction 17 605-611.

Liu RH, Sun QY, Li YH, Jiao LH \& Wang WH 2003 Maturation of porcine oocytes after cooling at the germinal vesicle stage. Zygote 11 299-305.

Li YH, Jiao LH, Liu RH, Chen XL, Wang H \& Wang WH 2004 Localization of angiotensin II in pig ovary and its effects on oocyte maturation in vitro. Theriogenology 61 447-459.

Matzuk MM \& Lamb DJ 2002 Genetic dissection of mammalian fertility pathways. Nature Medicine 8 (Suppl) S33-S40.

Meirow D, Levron J, Eldar-Geva T, Hardan I, Fridman E, Zalel Y, Schiff E \& Dor J 2005 Pregnancy after transplantation of cryopreserved ovarian tissue in a patient with ovarian failure after chemotherapy. New England Journal of Medicine 353 318-321.

Nagy A, Gersenstein M, Vintersten K \& Behringer R 2003 Manipulating the Mouse Embryo: A Laboratory Manual, 3rd Ed. New York: Cold Spring Harbour Laboratory Press.

Oktay K, Economos K, Kan M, Rucinski J, Veeck L \& Rosenwaks Z 2001 Endocrine function and oocyte retrieval after autologous transplantation of ovarian cortical strips to the forearm. JAMA 286 1490-1493.

Oktay K, Buyuk E, Rosenwaks Z \& Rucinski J 2003 A technique for transplantation of ovarian cortical strips to the forearm. Fertility and Sterility $80193-198$.

Oktay K, Buyuk E, Veeck L, Zaninovic N, Xu K, Takeuchi T, Opsahl M \& Rosenwaks Z 2004 Embryo development after heterotopic transplantation of cryopreserved ovarian tissue. Lancet 363 837-840.

Oktay KH \& Yih M 2002 Preliminary experience with orthotopic and heterotopic transplantation of ovarian cortical strips. Seminars in Reproductive Medicine 20 63-74.

Payton RR, Romar R, Coy P, Saxton AM, Lawrence JL \& Edwards JL 2004 Susceptibility of bovine germinal vesicle-stage oocytes from antral follicles to direct effects of heat stress in vitro. Biology of Reproduction 71 1303-1308.

Petroianu A, de Souza Vasconcellos L, Alberti LR, Fonseca de Castro LP \& Barbosa Leite JM 2002 Natural pregnancy in rabbits that underwent oophorectomy and orthotopic allogeneic or autologous ovarian transplantation. Fertility and Sterility 77 1298-1299.

Petroianu A, de Souza Vasconcellos L, Alberti LR \& Buzelin Nunes M 2005 The influence of venous drainage on autologous ovarian transplantation. Journal of Surgical Research 124 175-179.

Radford JA, Lieberman BA, Brison DR, Smith AR, Critchlow JD, Russell SA, Watson AJ, Clayton JA, Harris M, Gosden RG et al.
2001 Orthotopic reimplantation of cryopreserved ovarian cortical strips after high-dose chemotherapy for Hodgkin's lymphoma. Lancet $3571172-1175$.

Salle B, Demirci B, Franck M, Rudigoz RC, Guerin JF \& Lornage J 2002 Normal pregnancies and live births after autograft of frozenthawed hemi-ovaries into ewes. Fertility and Sterility 77 403-408.

Salle B, Demirci B, Franck M, Berthollet C \& Lornage J 2003 Longterm follow-up of cryopreserved hemi-ovary autografts in ewes: pregnancies, births, and histologic assessment. Fertility and Sterility $80172-177$.

Shaw JM, Cox SL, Trounson AO \& Jenkin G 2000 Evaluation of the long-term function of cryopreserved ovarian grafts in the mouse, implications for human applications. Molecular and Cellular Endocrinology 161 103-110.

Siegel-Itzkovich J 2005 Woman gives birth after receiving transplant of her own ovarian tissue. BMJ 33170.

Snow M, Cox SL, Jenkin G, Trounson A \& Shaw J 2002 Generation of live young from xenografted mouse ovaries. Science 2972227.

Snow M, Cox SL, Jenkin G \& Shaw J 2004 Fertility of mice following receipt of ovaries slow cooled in dimethyl sulphoxide or ethylene glycol is largely independent of cryopreservation equilibration time and temperature. Reproduction, Fertility, and Development 15 407-414.

Sun XF, Wang WH \& Keefe DL 2004a Overheating is detrimental to meiotic spindles within in vitro matured human oocytes. Zygote 12 65-70.

Sun XF, Zhang WH, Chen XJ, Xiao GH, Mai WY \& Wang WH 2004b Spindle dynamics in living mouse oocytes during meiotic maturation, ageing, cooling and overheating: a study by polarized light microscopy. Zygote 12 241-249.

Wang X, Bilolo KK, Qi S, Xu D, Jiang W, Vu MD \& Chen H 2002a Restoration of fertility in oophorectomized rats after tubo-ovarian transplantation. Microsurgery 22 30-33.

Wang X, Chen H, Yin H, Kim SS, Lin Tan S \& Gosden RG 2002b Fertility after intact ovary transplantation. Nature $\mathbf{4 1 5} 385$.

Waterhouse T, Cox SL, Snow M, Jenkin G \& Shaw J 2004 Offspring produced from heterotopic ovarian allografts in male and female recipient mice. Reproduction 127 689-694.

Yamashita M, Mita K, Yoshida N \& Kondo T 2000 Molecular mechanisms of the initiation of oocyte maturation: general and speciesspecific aspects. Progress in Cell Cycle Research 4 115-129.

Yoshimura Y 1997 The ovarian renin-angiotensin system in reproductive physiology. Frontiers in Neuroendocrinology 18 247-291.

Younis JS, Skournik A, Radin O, Haddad S, Bar-Ami S \& Ben-Ami M 2005 Poor oocyte retrieval is a manifestation of low ovarian reserve. Fertility and Sterility 83 504-507.

Received 12 August 2005

First decision 17 November 2005

Revised manuscript received 23 January 2005

Accepted 25 January 2006 